Original Article

\title{
METHOD DEVELOPMENT, VALIDATION AND STABILITY STUDIES FOR DETERMINATION OF BUMETANIDE IN BULK AND PHARMACEUTICAL DOSAGE FORM BY RP-UPLC
}

\author{
CHAITANYA BONI, RAJA SUNDARARAJAN* \\ GITAM Institute of Pharmacy, GITAM (Deemed to be University), Visakhapatnam-Andhra Pradesh, India Pincode 530045 \\ Email: sraja61@gmail.com
}

Received: 18 Nov 2017 Revised and Accepted: 11 Jan 2018

\begin{abstract}
Objective: The objective of the study was to develop a new, simple, accurate, precise and reproducible RP-UPLC method for the estimation of bumetanide in bulk and pharmaceutical dosage form.

Methods: Acquity SB C18, 2 × $100 \mathrm{~mm}, 1.8 \mu \mathrm{mm}, 5 \mu$ particle size column with the mobile phase consisting of water: acetonitrile in the ratio of $30: 70$ $\mathrm{v} / \mathrm{v}$ were used. The effluents were moniRTat $254 \mathrm{~nm}$ and the flow rate was $1.0 \mathrm{ml} / \mathrm{minute}$.

Results: The retention time was $0.852 \mathrm{~min}$. Quantitative linearity was obeyed in the concentration range of 12.5 to $75 \mu \mathrm{g} / \mathrm{ml}$. The correlation coefficient for bumetanide was found to be 0.999 . Recovery and assay studies of bumetanide were within 99 to $102 \%$, indicating that the proposed method can be adaptable for quality control analysis of bumetanide. The \% RSD for precision and accuracy of the method was found to be less than $2 \%$. Bumetanide was subjected to stress environment of degradation in aqueous solutions including oxidation, hydrolysis, thermal and photolysis degradation.
\end{abstract}

Conclusion: Proposed method was found to be simple, accurate, precise, and quick and can be used for regular analysis. This condition was applied to tablet dosage form. The statistical parameters and recovery studies were reported.

Keywords: UPLC, Bumetanide, Method development, ICH Guidelines

(C) 2018 The Authors. Published by Innovare Academic Sciences Pvt Ltd. This is an open access article under the CC BY license (http://creativecommons.org/licenses/by/4.0/) DOI: http://dx.doi.org/10.22159/ijpps.2018v10i3.23728

\section{INTRODUCTION}

The best way to illustrate the quality of a drug substance is to verify its purity. The basic task of pharmaceutical studies includes how to assure the quality safety and efficacy of drugs [1]. The quality of the drugs encompasses the potency, uniformity, purity, pharmacological action, stability etc. Therefore, it becomes essential for the manufacturer to maintain the quality and produce effective safe and non-toxic forms of drugs by developing newer analytical methods. The methods of identification, estimation of drug substances and drug products are divided into physical, chemical, physicochemical and biological. Physical methods of analysis involve the use of physical reactions between the analyte and reagent. Physicochemical methods are used to study the physical phenomena that take place as a result of chemical reactions [2]. The techniques are usually based on the study of optical (emission, e. g., fluorimetry), absorption (UV, visible, IR spectrophotometry), electrochemical (potentiometry, amperometry, polarography) characteristics and chromatographic mode (HPLC, GLC, HPTLC) which include separation and quantification (e. g. photodiode array detector). The chromatography is very popular technique and it is frequently used analytically. There are various types of chromatographic techniques namely paper chromatography, gas chromatography, liquid chromatography, thin layer chromatography (TLC), ion exchange chromatography, high-performance liquid chromatography (HPLC) and ultra-performance liquid chromatography (UPLC) [3]. High-performance liquid chromate-graphy which is also called as high-pressure liquid chromatography. It is a popular analytical technique used for the separation, identification, and quantification of each constituent of the mixture. HPLC is a highly developed technique for column liquid chromatography. The solvent generally flows through a column with the assist of gravity but in HPLC technique the solvent is forced under high pressures up to 400 atmospheres. Hence that sample can be separated into different constituents with the assist of difference in relative affinities. In HPLC, pumps are used to pass pressurized liquid solvent. It also includes the sample mixture which is permitted to enter into a column filled with solid adsorbent material. The interaction of every sample component varies which causes a difference in flow rates of each component and finally leads to separation of components in column [4]. UPLC is a modern technique which gives a new approach for liquid chromatography. UPLC develops primarily in three areas: speed, resolution, and sensitivity [5]. UPLC shows an extraordinary development in speed, resolution as well as the sensitivity of analysis by using particle size less than $2 \mu \mathrm{m}$ and the system is operational at higher pressure. The mobile phase can be able to run at better linear velocities as compared to HPLC [6]. This practice is considered as a new central point in the field of liquid chromatographic studies [7].

Bumetanide is a loop diuretic used to treat heart failure. The world antidoping agency (WADA) and national football league (NFL) consider the supplement a banned ingredient for athletes. Its alleged use is to disguise steroids by increasing urine output. Bumetanide [3-(Aminosulfonyl)-5(butylamino)-4-phenoxy-benzoic] acid is a potent high-ceiling or loop diuretic that has an efficiency 40 to 60 times greater than furosemide [8]. The chemical formula and molecular weight of bumetanide are $\mathrm{C}_{17} \mathrm{H}_{20} \mathrm{~N}_{2} \mathrm{O}_{5} \mathrm{~S}$ and 364.416 respectively. This compound belongs to the sulfonamide family, although its structure differs considerably from furosemide and others of its class. The main aim and objective of this work was method development, validation and degradation studies of bumetadnide in pharmaceutical dosage form by RP-UPLC.

\section{MATERIALS AND METHODS}

\section{Instrumentation}

UPLC instrument used was of WATERS UPLC 2965 SYSTEM with auto-injector and PDA detector. Software used was Empower 2. UVVIS spectrophotometer PG Instruments T60 with special bandwidths of $2 \mathrm{~mm}$ and $10 \mathrm{~mm}$ and matched quartz was used for measuring absorbance for bumetanide solutions.

\section{Chemicals}

HPLC grade acetonitrile, orthophosphoric acid, and all other chemicals were purchased from Rankem chemical division, Hyderabad. HPLC grade water was used throughout the study. 


\section{Preparation of orthophosphoric acid (0.1\%)}

0.1 gms of orthophosphoric acid was accurately weighed and transferred to a $1000 \mathrm{ml}$ volumetric flask. Then $1000 \mathrm{ml}$ of water was added to the volumetric flask and degassed for removal of water bubbles.

\section{Preparation of mobile phase}

Buffer solution and HPLC grade acetonitrile were transferred to the volumetric flask in the ratio of 30:70. Prior to use, the mobile phase was degassed in an ultrasonic water bath for $5 \mathrm{~min}$ and the solution was filtered through $4.5 \mu$ filter paper under vacuum filtration.

\section{Standard solution preparation}

Bumetanide (5 mg) was accurately weighed and transferred into a $10 \mathrm{ml}$ clean dry volumetric flask and $7 \mathrm{ml}$ of diluents was added. The solution was sonicated for $30 \mathrm{~min}$ and made up to the final volume with diluents. From the above solution, $1 \mathrm{ml}$ was transferred to 10 $\mathrm{ml}$ volumetric flask and then made up to final volume with diluents.

\section{Sample preparation}

Twenty tablets were weighed and calculated the average weight of each tablet. Then the weight equivalent to 1 tablet was transferred to a $100 \mathrm{ml}$ volumetric flask. Diluents $(80 \mathrm{ml})$ were added and sonicated for $25 \mathrm{~min}$. Then the volume was made up of diluents and filtered. From the filtered solution, $1 \mathrm{ml}$ was transferred to $10 \mathrm{ml}$ volumetric flask and made up to final volume with diluent.

\section{Method development}

Initially, reverse phase liquid chromatography separation was tried to develop using various ratios of water: methanol and acetonitrile as mobile phases, in which the drug did not respond properly and the resolution was also poor. The organic content of mobile phase was also investigated to optimize the separation of the drug. Thereafter, orthophosphoric acid: acetonitrile were taken in 30:70\% $\mathrm{v} / \mathrm{v}$ at a flow rate of $0.4 \mathrm{ml} / \mathrm{min}$. Acquity SB C18, $2 \times 100 \mathrm{~mm}, 1.8$ $\mu \mathrm{mm}, 5 \mu$ particle size column was used as the stationary phase. It was selected to improve resolution and the tailing of both peaks which were reduced considerably and brought close to 1.5 . Detection was tried at various wavelengths from $210 \mathrm{~nm}$ to $280 \mathrm{~nm}$ for drug analysis. The wavelength at which bumetanide showed maximum absorption at $254 \mathrm{~nm}$ was selected as the detection wavelength for PDA detector. The retention times were found to about $0.852 \mathrm{~min}$. The obtained chromatogram was shown in fig. 5 .

\section{Method validation}

\section{System suitability}

Sample solution and six replicate injections were injected from freshly prepared standard solutions. Each solute was analyzed for their peak area, theoretical plates $(\mathrm{N})$, resolution $(\mathrm{R})$ and tailing factors [9].

\section{Linearity}

Five solutions ranging from $12.5-75 \mu \mathrm{g} / \mathrm{ml}$ were prepared. Each experiment was performed in triplicate according to the optimized chromatographic situation. The peak area of the chromatograms was plotted against the concentration of bumetanide to obtain the calibration curve [10].

\section{Precision}

Precision was determined as repeatability and intermediate precision by analyzing the samples in accordance with ICH guidelines. Determinations were performed on the same day as well as well as on consequent days [11]. Each stage of precision was investigated by 3 sequential replicates of injections of concentrations of 50,100 and $200 \mu \mathrm{g} / \mathrm{ml}$. The precision was expressed as the relative standard deviation (RSD).

\section{Repeatability}

Bumetanide sample solutions of $10 \mu \mathrm{g} / \mathrm{ml}$ concentration were spiked for repeatability of the method. The precision was examined by analyzing six replicates. The retention time and percentage relative standard deviation were calculated.

\section{Intermediate precision}

The intermediate precision was studied on the next day of sample preparation. Working standard solution (50 $\mathrm{ppm})$ of bumetanide at three concentration levels (50\%, $100 \%$, and $150 \%$ ) was analyzed. The \% RSD of the analytical responses was calculated.

\section{Accuracy}

The study of recovery of bumetanide was evaluated in triplicate at three concentration levels, i.e. $50 \%, 100 \%$ and $150 \%$ of working concentration of the sample [12]. The percentage of recoveries were calculated.

\section{LOD and LOQ}

A series of solutions were injected and the signal-to-noise ratio for each compound was calculated. This process was continued until the $\mathrm{S} / \mathrm{N}$ ratio was 3 for LOD and 10 for LOQ.

\section{Robustness}

Robustness was carried by varying three parameters from the optimized chromatographic conditions such as flow rate \pm \pm 0.1 $\mathrm{ml} / \mathrm{min}$ ), mobile phase composition $( \pm 5 \%$ ) and column temperature $\left( \pm 5^{\circ} \mathrm{C}\right)[13]$.

\section{Degradation studies}

\section{Oxidation}

The stock solution of bumetanide $(1 \mathrm{ml})$ was mixed with $1 \mathrm{ml}$ of $20 \%$ hydrogen peroxide $\left(\mathrm{H}_{2} \mathrm{O}_{2}\right)$. The solutions were kept for $30 \mathrm{~min}$ at $60^{\circ} \mathrm{c}$. For UPLC study, the resultant solution was diluted to obtain $50 \mu \mathrm{g} / \mathrm{ml}$ solution and $1.0 \mu \mathrm{l}$ was injected into the system. The chromatograms were recorded to assess the stability of the sample.

\section{Acid degradation studies}

The Stock solution of bumetanide ( $1 \mathrm{ml}$ ) was mixed with $1 \mathrm{ml}$ of $2 \mathrm{~N}$ hydrochloric acid and refluxed for $30 \mathrm{~min}$ at $60^{\circ} \mathrm{C}$. The resultant solution was diluted to obtain $50 \mu \mathrm{g} / \mathrm{ml}$ solution and injected into the system. The chromatograms were recorded to assess the stability of the sample.

\section{Alkali degradation studies}

The stock solution bumetanide $(1 \mathrm{ml})$ was mixed with $1 \mathrm{ml}$ of $2 \mathrm{~N}$ sodium hydroxide and refluxed for $30 \mathrm{~min}$ at $60^{\circ} \mathrm{C}$. The resultant solution was diluted to obtain $50 \mu \mathrm{g} / \mathrm{ml}$ solution and injected into the system. The chromatograms were recorded to assess the stability of the sample.

\section{Dry heat degradation studies}

The standard drug solution was placed in an oven at $105^{\circ} \mathrm{C}$ for $6 \mathrm{~h}$ for dry heat degradation studies. For UPLC study, the resultant solution was diluted to $50 \mu \mathrm{g} / \mathrm{ml}$ solution and $1.0 \mu \mathrm{l}$ was injected into the system and the chromatograms were recorded to assess the stability of the sample.

\section{Photostability studies}

$500 \mu \mathrm{g} / \mathrm{ml}$ solution was prepared and exposed to UV light by keeping the beaker in UV Chamber for 1day. For UPLC study, the resultant solution was diluted to $50 \mu \mathrm{g} / \mathrm{ml}$ solutions and was injected into the system. The chromatograms were recorded to assess the stability of the sample.

\section{Neutral degradation studies}

Stress testing under neutral conditions was studied by refluxing the drug in water for 1 hour at a temperature of $60^{\circ}$. For UPLC study, the resultant solution was diluted to $50 \mu \mathrm{g} / \mathrm{ml}$ solution and injected into the system. The chromatograms were recorded to assess the stability of the sample.

\section{Assay}

Standard solution and sample solution were injected into the chromatographic system and the peak area response for the analytes was measured. Standard preparations are made from the API and sample preparations are prepared from the formulation. Both sample and standard preparations were analyzed in six 
replicates. Standard was taken as the reference for the estimation of the drug in the formulation.

\section{RESULTS}

Chromatograms depicting the method development of bumetanide

Different chromatographic conditions were experimented to achieve the better efficacy of the chromatographic system. Parameters such as mobile phase composition, the wavelength of detection, column, column temperature, $\mathrm{pH}$ of mobile phase and diluents were optimized. Several proportions of buffer and solvents were evaluated in order to obtain an appropriate composition of the mobile phase. Choice of retention time, tailing, theoretical plates and runtime were major tasks while developing the method. A perfect peak was eluted at 30:70 (buffer: solvent) in an isocratic mobile phase flow rate. All the trails and the typical chromatogram obtained for bumetanide are shown in fig. 1-5.

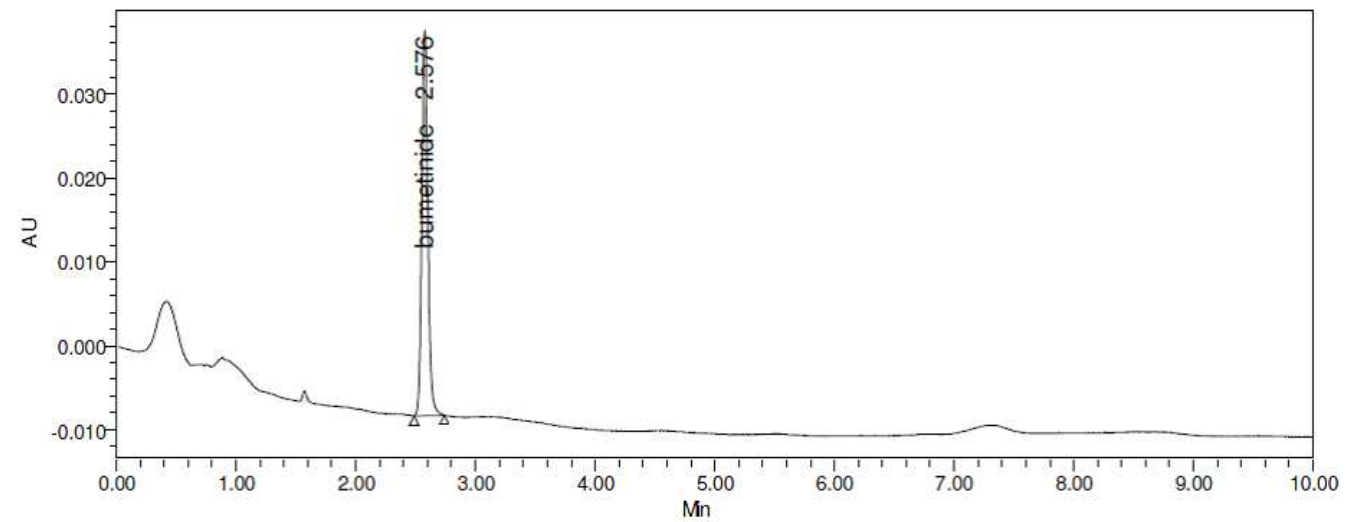

Fig. 1: First trail run of bumetanide

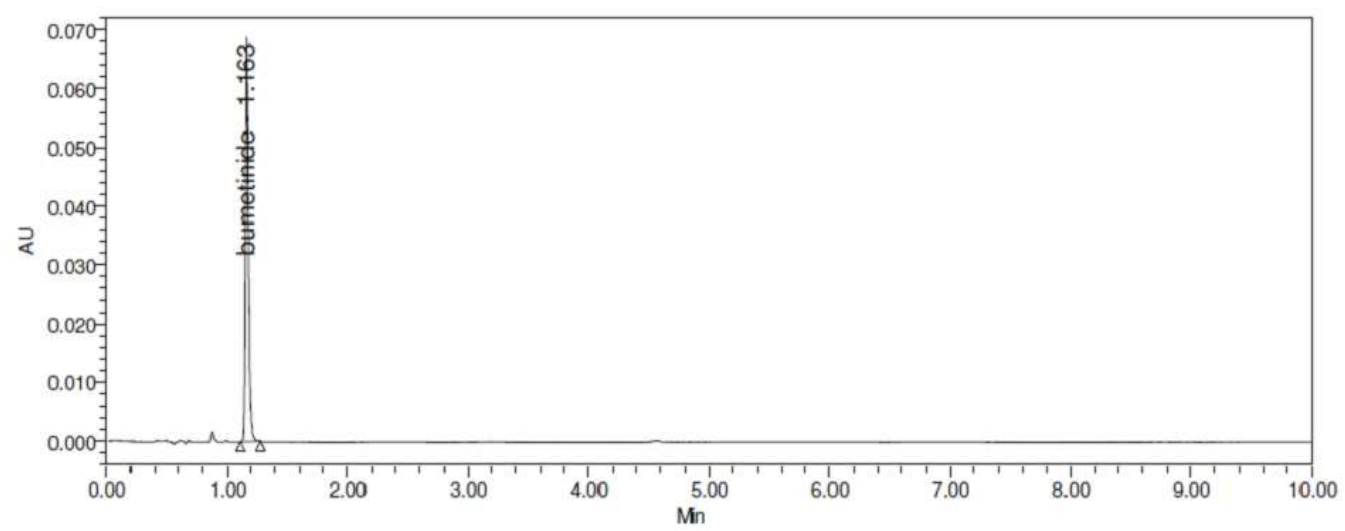

Fig. 2: Second trail run of bumetanide

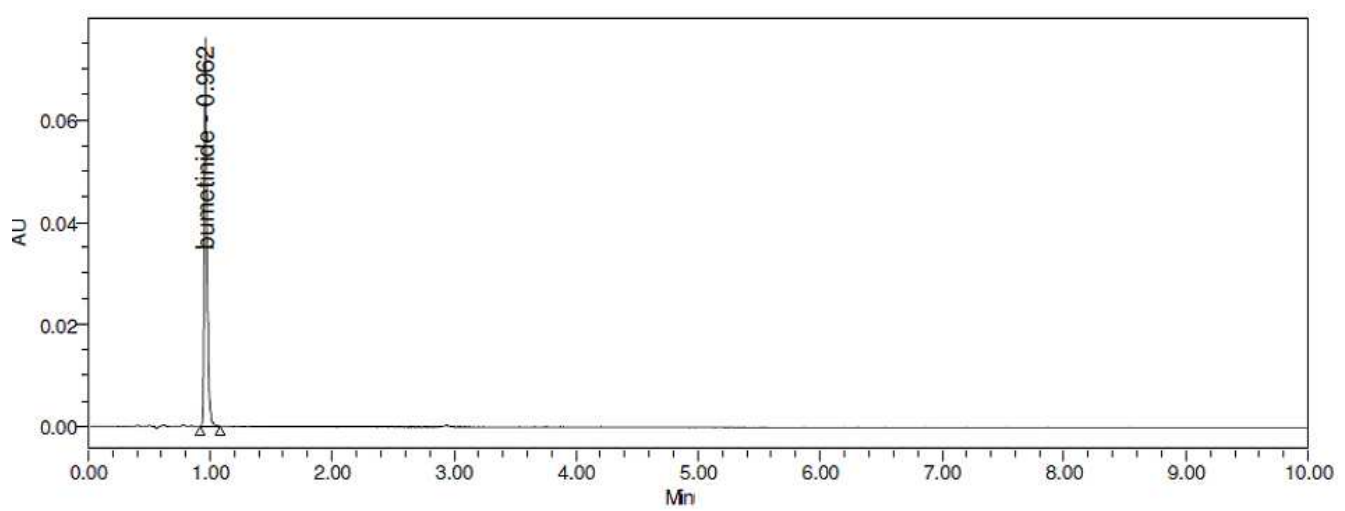

Fig. 3: Third trail run of bumetanide

\section{System suitability}

System suitability parameters such as retention factor (0.852), plate number (9177), tailing factor (1.5), RSD (1.0), standard deviation (907.8) and mean area (132667) were evaluated for six replicate injections of the drug.

The results were given in table 1. 


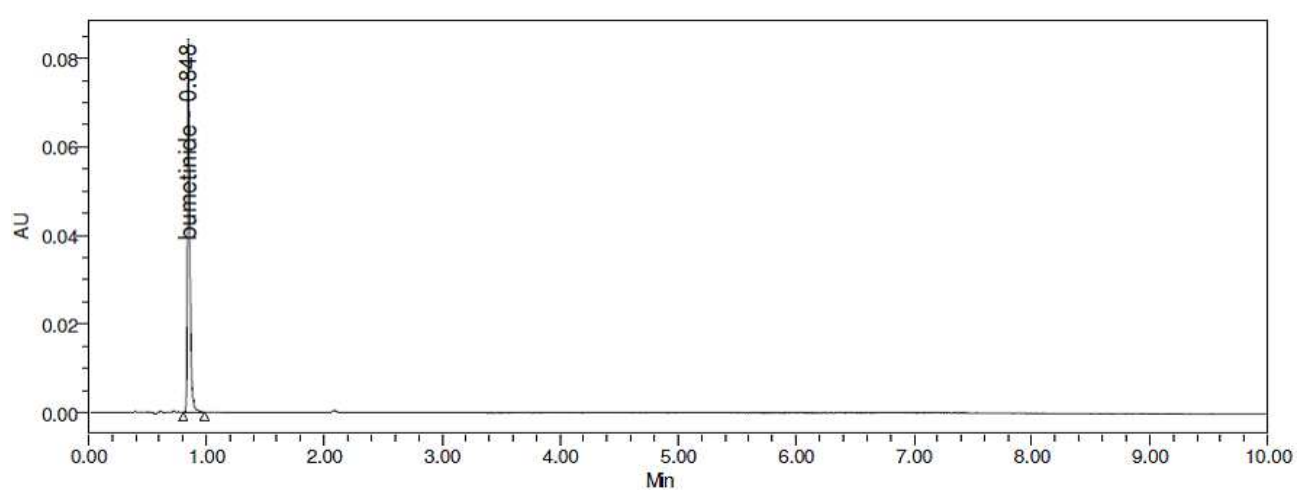

Fig. 4: Fourth trail run of bumetanide

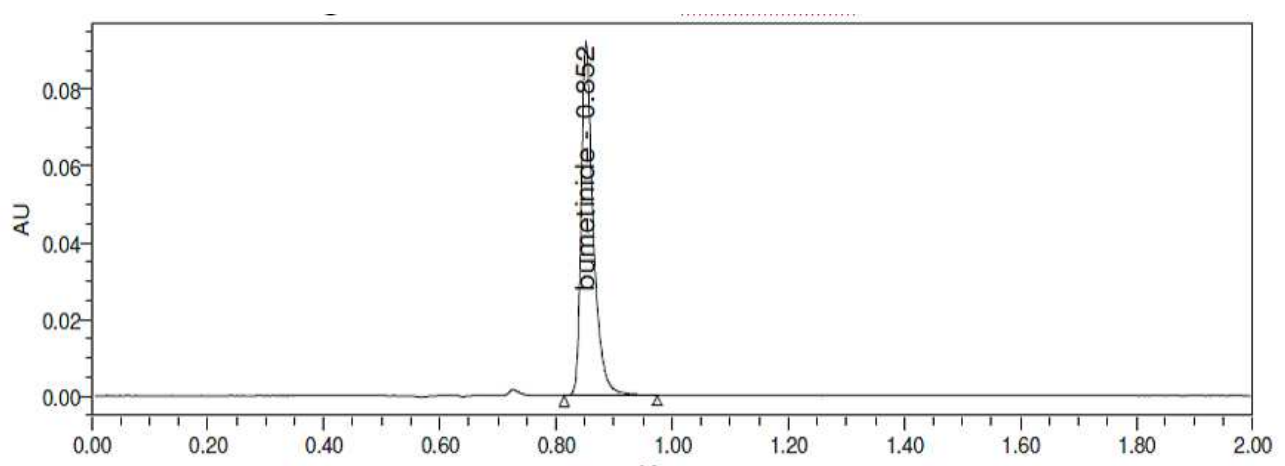

Fig. 5: Typical chromatogram of bumetanide by the proposed method

Table 1: System suitability data of bumetanide

\begin{tabular}{ll}
\hline Parameter & Result \\
\hline RT & $0.852 \mathrm{~min} / \mathrm{ml}$ \\
Area(mean) & 132667 \\
USP plate count & 9177 \\
USP tailing & 1.5 \\
*Standard deviation & 907.8 \\
\%RSD & 1.0 \\
\hline
\end{tabular}

*Number of experiments: 6, \% RSD: Relative standard deviation

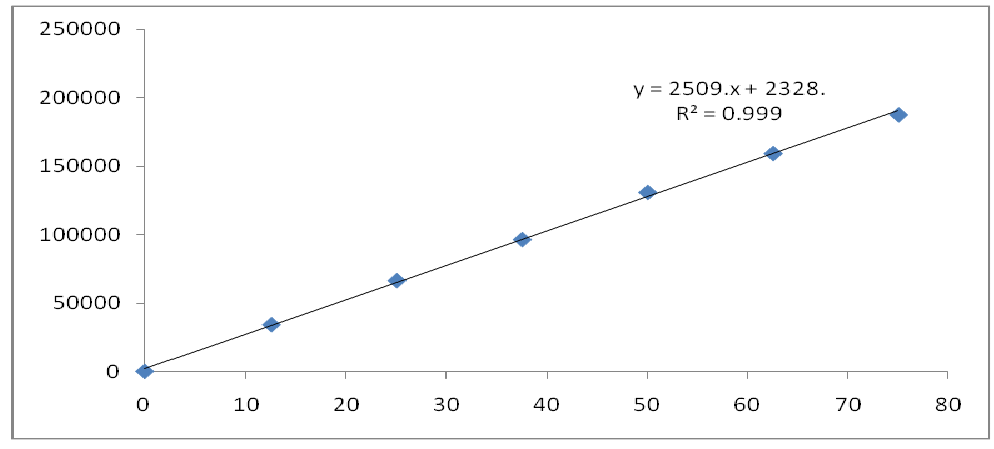

Fig. 6: Linearity plot of bumetanide

Table 2: linearity concentration and response

\begin{tabular}{lll}
\hline Linearity level (\%) & Concentration (ppm) & Area \\
\hline 0 & 0 & 0 \\
25 & 12.5 & 34131 \\
50 & 25 & 66387 \\
75 & 37.5 & 96431 \\
100 & 50 & 130931 \\
125 & 62.5 & 159408 \\
150 & 75 & 187732 \\
\hline
\end{tabular}




\section{Linearity}

A linear correlation was obtained between the peak area used and the absorbance Vs concentrations of bumetanide. The calibration curve was linear for concentrations between 12.5 and $75 \mu \mathrm{g} / \mathrm{ml}$.

The linearity of the calibration curves was validated by the values of the regression correlation coefficients $\left(r^{2}\right)$. The correlation coefficient was found to be 0.999 . The results of the linearity experiment were listed in table 2 and plot was presented in fig. 6 .

\section{Precision}

The \% RSD for the repeatability and intraday precision was reported to be 0.1 and 0.7 . The results of precision were shown in table 3 and 4.

Table 3: Repeatability data

\begin{tabular}{ll}
\hline S. No. & Peak area \\
\hline 1 & 131625 \\
2 & 134117 \\
3 & 132905 \\
4 & 134057 \\
5 & 130849 \\
6 & 131659 \\
${ }^{*}$ Average & 132535 \\
Standard deviation & 1370.7 \\
\hline
\end{tabular}

*Number of experiments-6, \%RSD: Relative standard deviation

Table 4: Intermediate precision

\begin{tabular}{ll}
\hline S. No. & Peak area \\
\hline 1 & 131257 \\
2 & 134055 \\
3 & 132542 \\
4 & 132537 \\
5 & 133017 \\
6 & 132505 \\
${ }^{*}$ Average & 132652 \\
Standard deviation & 904.8 \\
\hline
\end{tabular}

*Number of experiments-6, \% RSD: Relative standard deviation

\section{Accuracy}

The mean \% recovery at concentrations ranging from (spike level) $50 \%, 100 \%, 150 \%$ was found to be 98.02 to 100.32 which were in the acceptance limit of 98.0 to $102.0 \%$. The RSD was not more than $2.0 \%$. The results were shown in table 5 .

\section{Robustness}

The robustness method was evaluated by deliberately varying the chromatographic conditions. The \% RSD of flow minus, flow plus, mobile phase minus, mobile phase plus, temperature minus and temperature plus were found to be $0.6,1.6,0.8,0.7,1.0,0.4$ respectively. The parameters like tailing factor and retention time showed adherence to the limits. The data obtained with these changes were mentioned in table 6.

\section{LOD and LOQ}

Ratios of 3:1 and 10:1 signal-to-noise were considered as acceptable criteria for estimation of the LOD and LOQ, respectively. So, the limit of detection and the limit of quantification were determined to be 0.84 and $0.27 \mu \mathrm{g} / \mathrm{ml}$, respectively. Chromatograms showing LOD and LOQ were as shown in fig. 7 and 8.

\section{Forced degradation studies}

Degradation studies were performed with the formulation and degraded samples were injected.

The \% degradation of the drug for acid, alkali, oxidation, thermal, UV and water were $4.54,2.92,1.81,0.86,0.89,0.52$, respectively. Data was recorded in table 7.

Table 5: Recovery of assay method

\begin{tabular}{llll}
\hline Level & Amount spiked $(\boldsymbol{\mu g} / \mathbf{m l})$ & \% recovery & Mean \% recovery \\
\hline $50 \%$ & 25 & 99.40 & \\
& 25 & 98.02 & \\
$100 \%$ & 25 & 99.71 \\
& 50 & 99.51 \\
$150 \%$ & 50 & 99.14 \\
& 75 & 98.96 \\
& 75 & 99.58 \\
& 75 & 99.00 & \\
\hline
\end{tabular}

*Number of experiments: 3, \% RSD: Relative standard deviation 
Table 6: Robustness data of bumetanide

\begin{tabular}{lc}
\hline Parameter & \%RSD $^{*}$ \\
\hline Flow Minus & 0.6 \\
Flow Plus & 1.6 \\
Mobile phase Minus & 0.8 \\
Mobile phase Plus & 0.7 \\
Temperature minus & 1.0 \\
Temperature plus & 0.4 \\
\hline
\end{tabular}

Number of experiments: 3, \%RSD: Relative standard deviation

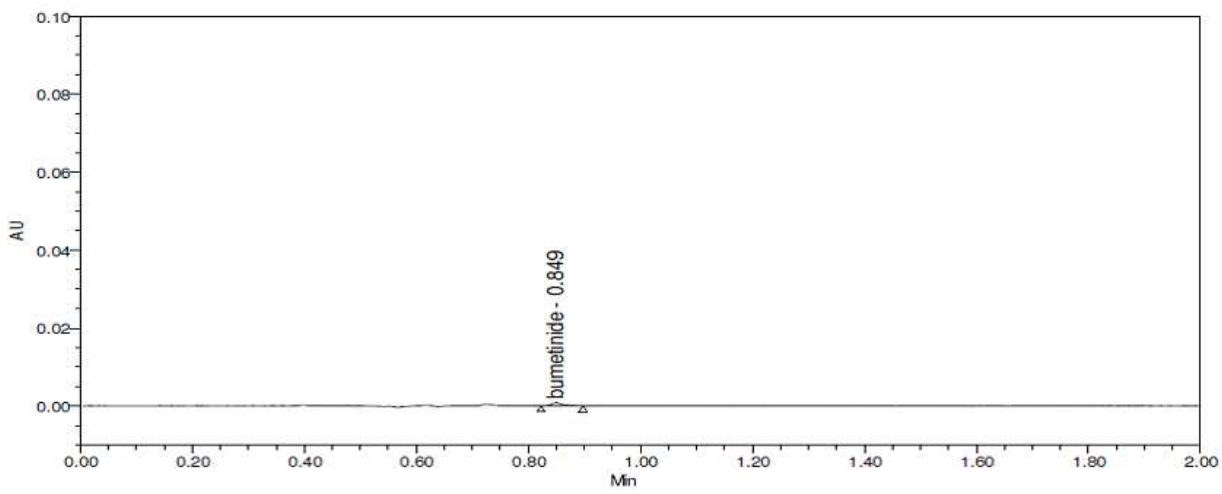

Fig. 7: LOD chromatogram of bumetanide

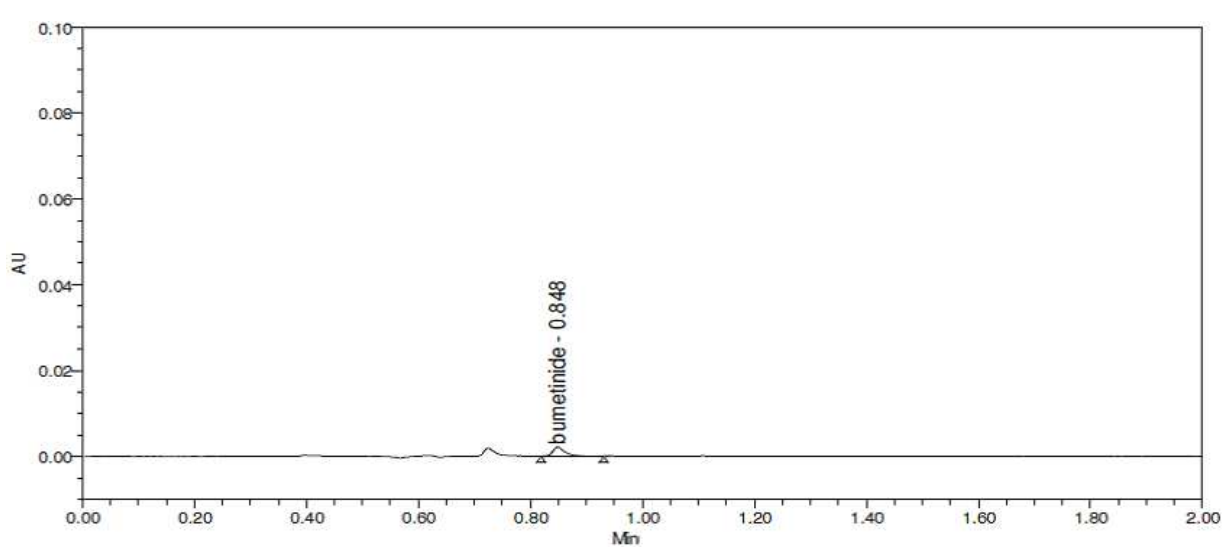

Fig. 8: LOQ chromatogram of bumetanide

Table 7: Forced degradation studies of bumetanide

\begin{tabular}{lll}
\hline S. No. & Degradation condition & \% drug degraded \\
\hline 1 & Acid & 4.54 \\
2 & Alkali & 2.92 \\
3 & Oxidation & 1.81 \\
4 & Thermal & 0.86 \\
5 & UV & 0.89 \\
6 & Water & 0.52 \\
\hline
\end{tabular}

Table 8: Assay of formulation of bumetanide

\begin{tabular}{ll}
\hline Sample No. & \% assay \\
\hline 1 & 98.9 \\
2 & 100.8 \\
3. & 99.9 \\
4. & 100.7 \\
5. & 98.3 \\
6. & 98.9 \\
Average & 99.60 \\
Standard deviation & 1.03 \\
\%RSD & 1.03 \\
\hline
\end{tabular}

*Number of experiments-6, \% RSD: Relative standard deviation 


\section{Assay of marketed formulation}

Standard solution and sample solution were injected separately into the system. The \% RSD of the marketed formulation was found to be 1.03. The drug present in the sample was calculated and results were summarized in table 8 .

\section{DISCUSSION}

Analytical method development helps to know the vital process parameters and to reduce their influence on accuracy and precision. Analytical methods must be used by following GMP and GLP guiding principles and must be developed using the protocols and acceptance criteria set out in the ICH guidelines Q2 (R1). Method validation helps to validate the analytical method for a diversity of concentrations so that the change in formulation or concentration does not need additional validation. Once the methods have been developed, qualified and validated the impact they have on out-ofspecification rates and process capability needs to be quantified. Methods are evaluated to determine its effectiveness for future use [14]. Several mobile phase compositions were tried to develop a new RP-UPLC method. A satisfactory separation with good peak symmetry was obtained with aquity SB C18, 2x100 mm, $1.8 \mu \mathrm{mm}, 5 \mu$ column using mobile phase containing orthophosphoric acid: acetonitrile (30:70) $(\mathrm{v} / \mathrm{v})$ at a flow rate of $0.4 \mathrm{ml} / \mathrm{min}$. Quantification was achieved at UV detection at $254 \mathrm{~nm}$ based on peak area. The retention time for bumetanide was found to be $0.852 \mathrm{~min}$. The optimized method was validated as per ICH guidelines.

System suitability tests were an integral part of a liquid chromatographic technique. They were used to verify that the proposed method was able to produce good resolution between the peaks of interest with high reproducibility. Retention factor, plate number $(\mathrm{N})$, tailing factor $(\mathrm{T})$, and RSD evaluated were within the range of acceptable limits [15]. The accuracy of an analytical procedure expresses the closeness of agreement between the value which is accepted either as a conventional true value or an accepted reference value and the value found [16]. The standard addition and recovery experiments were conducted to demonstrate the accuracy of the method. The values of \% recovery were found to be $99.29 \%$, indicates that the method was accurate.

The precision of an analytical method gives information on the random error. It expresses the agreement between a series of measurements obtained from multiple sampling of the same homogeneous sample under prescribed conditions. Six injections at the unchanged concentration were analyzed on the same day and two different days for verifying the variation in the precision. The $\%$ RSD for bumetanide was within the acceptable limit of $\leq 2$. Hence the method is reproducible on different days with different analyst and column. This indicates that the method was precise. The linearity of the method was tested in order to demonstrate the proportional relationship of response versus analyte concentration over the working range [17]. It is usual practice to perform linearity experiments over a wide range of analyte. This gives confidence that the response and concentration are proportional. It also accordingly ensures that calculation can be performed using a single reference standard/working standard, relatively than the equation of a calibration line. Bumetanide showed a linearity of response between $12.5-75 \mu \mathrm{g} / \mathrm{ml}$. These were represented by a linear regression equation as follows: $y=2509 . x+2328$. The regression line was established by least squares method. The correlation coefficient $\left(\mathrm{R}^{2}\right)$ for bumetanide was found to be greater than 0.999. Hence the curves established were linear.

The limit of detection (LOD) and limit of quantification (LOQ) were established based on the concentration of the analyte that would yield signal-to-noise ratios of 3 for LOD and 10 for LOQ respectively. LOD and LOQ were found to be $0.27 \mu \mathrm{g} / \mathrm{ml}$ and $0.80 \mu \mathrm{g} / \mathrm{ml}$ respectively. In all deliberately varied conditions, the SD of retention times of bumetanide was found to be well within the acceptable limit. The tailing factor for all the three peaks was found to $b e<1.5$. Robustness was carried by changing three parameters from the optimized chromatographic conditions such as making small changes in flow rate $( \pm 0.1 \mathrm{ml} / \mathrm{min})$, mobile phase composition $( \pm 5 \%)$ and column temperature $\left( \pm 5{ }^{\circ} \mathrm{C}\right)$. It was observed that the small changes in these operational parameters did not lead to changes of the retention time of the peak of interest and the \%RSD was not more than 2.0. The degree of reproducibility of the results proves that the method was robust. Specificity was tested by injecting the sample by spiking with suitable levels of impurities and indicating the separation of these impurities separately and/or from other components in the sample matrix. There are no placebo and excipients peaks interference with standard and analytic peak. So it proves method was selective.

\section{CONCLUSION}

Chromatographic conditions used were stationary phase equity $\mathrm{SB}$ C18 $2 \times 100 \mathrm{~mm}, 1.8 \mu$ column and a mobile phase consisting of $0.1 \%$ orthophosphoric acid: Acetonitrile in the ratio of 30:70. The flow rate was maintained at $1 \mathrm{ml} / \mathrm{min}$. The detection wavelength in UV was $254 \mathrm{~nm}$. The column temperature was $30^{\circ} \mathrm{C}$. System suitability parameters were reported by injecting the standard six times and results were well under the range of acceptance criteria. Linearity study was carried out between $25 \%$ to $150 \%$ levels were within acceptable range. Precision had shown good results which are acceptable to carry out a regular analysis. LOD and LOQ were found to be $0.27 \mu \mathrm{g} / \mathrm{ml}$ and $0.80 \mu \mathrm{g} / \mathrm{ml}$, respectively. By using above method, assay of the marketed formulation was carried out. The mean percentage of recovery of the formulation was $99.60 \%$. The Proposed method was found to be simple, accurate, precise, and quick and could be used for regular analysis. This condition was applied to tablet dosage form. The statistical parameters and recovery studies were reported. Degradation studies of bumetanide were done, in all conditions purity threshold was more than purity angle and within the acceptable range.

\section{ACKNOWLEDGEMENT}

The authors are thankful for the management of GITAM University, Visakhapatnam, Andhra Pradesh, India, for providing necessary facilities to carry out the research work.

\section{AUTHORS CONTRIBUTIONS}

The complete research work was suggested and designed by Raja Sundararajan. Method development and validation works were carried out by Chaitanya Boni. Further, the manuscript was drafted by Chaitanya Boni and it was edited by Raja Sundararajan. Authors read and approved the final manuscript.

\section{CONFLICT OF INTERESTS}

Authors declare no conflict of interest

\section{REFERENCES}

1. Masoom RS, Zeid AA, Nafisur R. Analytical techniques in pharmaceutical analysis: a review. Arab J Chem 2017;10:1409-21.

2. Sowjanya P. A brief review on validation of many drugs by using HPLC technique. Res Rev J Pharm Nanotechnol 2016;4:1-17.

3. Thammana M. A review on high-performance liquid chromatography (HPLC). Res Rev J Pharm Anal 2016;5:22-8.

4. Rogatsky E. Modern high-performance liquid chromatography. Int Sym J Chromatogr Sep Tech 2016;7:135.

5. Taleuzzaman M, Ali S, Gilani SJ, Imam SS, Hafeez A. Ultra performance liquid chromatography (UPLC)-a review. Austin J Anal Pharm Chem 2015;2:1-5.

6. Naresh K, Bhawani S, Maneesh KT. Ultra performance liquid chromatography. Int J Pharm Med Biol Sci 2014;3:84-94.

7. Kumar A, Saini G, Nair A, Sharma R. Uplc: A preeminent technique in pharmaceutical analysis. Acta Pol Pharm 2012;69:371-80.

8. Palleshwar RG, Rao J, Lanka A, Rama P, Srinivasu P. Development and validation of a new stability indicating HPLC method for quantification of process related and degradation impurities of bicalutamide in tablet dosage forms. Int J Pharm 2012;2:218-23.

9. Nasiruddin AF, Akalanka D, Singh GN, Easwari TS. Development and validation of reverse-phase high-performance liquid chromatography method for quantitative estimation of the vaccine in bulk and pharmaceutical dosage form. Asian J Pharm Clin Res 2014;7:235-40. 
10. Khaleel N, Abdul R. A validated stability indicating an RP-HPLC method for simultaneous estimation of tenofovir disoproxil fumarate, cobicistat, emtricitabine and elvitegravir in bulk and pharmaceutical dosage form. Int J Pharm 2015;5:991-1002.

11. Shrinivas S, Revanasiddappa M. Analytical stability indicative method development and validation by highpressure liquid chromatography for assay in ciprofloxacin hydrochloride drug substances. Am J Anal Chem 2015; 6:719-30.

12. Supriya P, Madhavi Latha N, Rohith KBV, Ramana GV, Harini U, Pawar AKM. Development and validation of UV spectrophotometric and RP-HPLC-PDA methods for the estimation of alogliptin benzoate. Asian J Pharm Clin Res 2016; 9:282-7.

13. Mitali VV, Chirag JP, Patel MM. Development and stability indicating HPLC method for dapagliflozin in API and pharmaceutical dosage form. Int J Appl Pharm 2017;9:33-41.
14. Hashem AA, Iman AB, Franc Ois K. Development and validation of a stability-indicating RP-HPLC method for the determination of levocabastine HCL in bulk drug and in ophthalmic suspensions. Arab J Chem 2017;10:3097-107.

15. Padma SS, Vidya VD. HPLC method development and validation for quantitation of trigonelline from mirabilis jalapa linn leaves and enhancement in extraction yield from ultra-fine powder. Int J Curr Pharm Res 2017;9:62-6.

16. Latha ST, Ananda TS, Jambulingam M, Sereya K, Kamalakannan D, Anilkumar M. Development and validation of an RP-HPLC method for the estimation of erlotinib in a pharmaceutical formulation. Arab J Chem 2017;10:1138-44.

17. Sunil G, Jambulingam M, Ananda TS, Kamalakannan D, Sundaraganapathy R, Jothimanivannan C. Development and validation of ketorolac tromethamine in an eye drop formulation by the RP-HPLC method. Arab J Chem 2017; 10:928-35. 